Pantaleón, que Alarcón,

que de un león no se espanta,

le espanta Pantaleón.

Finalmente, entre otros poemitas semejantes, pero esta vez anónimos, figura en el ms. 8252 de la B. N. M., fol. 68 , con variantes que prueban una transmisión oral, nada rara en un poemita breve y deliciosamente irónico:

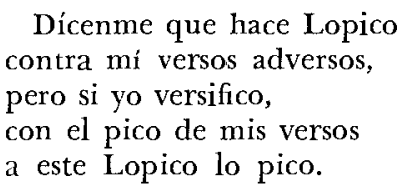

¿Serán de Góngora? Yo lo dudo mucho, puesto que de serlo tendríamos que atribuirle todos los que figuran como de ese desconocido Juan Navarro de Cascante, "poeta ridículo".

José Manuel Blecua

Zaragoza.

\title{
EL AUTOR DE LA CANCIÓN "UFANO, ALEGRE, ALTIVO, ENAMORADO”
}

En 1943 (RFE, 26, pp. 8o ss.) llamé la atención sobre el pequeño detalle de que el nombre de Mira de Amescua no figurase al frente de las mejores copias manuscritas de la célebre "Canción real a una mudanza" y que, en cambio, dos de los mejores mss. coincidiesen en señalar por autor a un Trevijano: "Canción real del Treuijano", rezaba un copia; al paso que en otra se leía: "Canción del Trebijano, caballero de Burgos", y hasta copiaba otra canción del mismo autor ${ }^{1}$. Mis diligencias por averiguar quién se escondía bajo ese nombre, que parecía seudónimo académico, no dieron ningún resultado hasta que en la Houghton Library de la Universidad de Harvard tuve ocasión de estudiar el ms. Span. 56 , copiado, quizá por el pintor Pacheco, suegro de Velázquez, en 1631, a juzgar por el título y el contenido. En los fols. 152-155 figuraba de nuevo la célebre canción con este encabezamiento: "Canción de don Joseph de Saravia, Secretario del Duque de Midina Sidonia, con nombre impuesto de Trevijano". Por fin quedaba aclarado un pequeño misterio. Todo lo demás era bastante sencillo.

En efecto, don José de Saravia fue en los años de 1628-16go, por lo menos, secretario del Duque de Medina Sidonia, pues figura como tal entre los amigos que elogian el Panegirico de Pedro Espinosa. Allí se dice que es "caballero de Santiago, señor de la villa de Eransus, secretario del Excelentísimo de Medina Sidonia, montero de cámara de Su Majestad"2. Y, conocido el dato de ser caballero de Santiago, nada

${ }^{1}$ Ms. 25o, fol. $678 \mathrm{v}^{\circ}$, de la Biblioteca Universitaria de Zaragoza, editado por mi con el título de Cancionero de 1628 (Madrid, 1945), y ms. 3913 de la B. N. M., fol. 11 .

${ }^{2}$ Obras de Pedro Espinosa, ed. de F. Rodriguez Marín, Madrid, 1909, p. 354. 
más sencillo que averiguar algo de sus antecedentes: a veinte de octubre de 1628 inició su expediente para la obtención del hábito, que le concedieron exactamente dos meses más tarde 3 .

Por este expediente sabemos que don José de Saravia fue "vecino y natural de Pamplona", hijo del capitán Pedro Saravia de la Riva, "vecino y natural de la villa de Espinosa de los Monteros, en las montañas de Burgos, y de doña Catalina de Ugarte, vecina y natural de Pamplona, en el reyno de Navarra". Por esas fechas andaba rondando los 35 años, poco más o menos, según frase acostumbrada. Domingo de la Raz declara que "será de más de treinta y seis años", mientras don León de la Rada, vecino también de Pamplona, asegura que "conoçe a don Joseph de Sarauia, pretendiente, que le pareçe que será hombre de treinta y quatro o treinta y seis años". Debió de nacer, por lo tanto, hacia $1589-1584$.

He aquí, pues, aclarado un pequeño problema de la poesía de la Edad de Oro, tan rica en problemas de todas clases, grandes y minúsculos, pero siempre apasionantes y curiosos ${ }^{4}$.

Zaragoza.

José Manuel Blecua

\section{DON GUINDO CEREZO Y PABLO DE OLAVIDE}

Pablo González Casanova, en su prólogo al volumen Sátira anónima del siglo xuiii (México, 1953, pp. 26-27), se refiere de paso a ciertas formas literarias que viajaban tanto, y con itinerarios tan complicados, que a veces nos quedamos sin saber cuál fue su exacto punto de partida:

Otro ejemplo -apasionante- de este comercio espiritual entre España e Indias cs el de El Siglo Ilustrado. Vida de don Guindo Cerezo, nacido, educado, instruido, sublimado y muerto, segin las luces del presente siglo. que para seguro modelo de las costumbres dio a luz don Justo Vera de la Ventosa. Se trata de una incógnita perfecta, con cuya solución no hemos dado a pesar de todos los esfucrzos realizados aquí y allá. ¿Quién es este Justo Vera de la Ventosa, autor de una novela picaresca de la Ilus. tración, que sólo conocemos manuscrita? Nos inclinamos a creer que es un español, per̃o pensar que fuera mexicano es algo que nos ha ocurrido a menudo. ¿Un predecesor de Lizardi? (...) ¿Vino de España la obra o de qué pueblo? Sabemos que en Toluca quemaron un ejemplar, por orden de la Inquisición, hacia el año de 1788; sabemos que el autor habla de "al otro lado de los montes", refiriéndose a Francia; sabemos que no incurre en mexicanismos, pero todavía hemos querido dudar, porque se trata de un libro semiculto y en ese terrcno es posible cobrar un aire internacional que, para el caso, no deja de ser hispánico. Sea lo que fuere, éste, como el anterior ejcmplo, da una idea del movimiento espiritual que hay entre España y México, y que se lleva a cabo por medio de

3 Archivo Histórico Nacional, Santiago, leg. 631,7653.

Agradezco al profesor Avalle Arce las molestias que le causé con la copia de la famosa canción, y a Mr. William A. Jackson, director de la Houghton Library, por las facilidades dadas para el estudio del manuscrito. 